\title{
Functional tricuspid valve insufficiency after cardiac transplantation: Which factor is the most important?
}

\author{
Vüsal Hajiyev, MD, ${ }^{\mathrm{a}}$ Michael Dandel, MD, PhD ${ }^{\mathrm{a}, \mathrm{b}}$ Ruhi Yeter, MD, ${ }^{\mathrm{a}}$ Felix Schoenrath, MD, PhD,
} Felix Hennig, MD, ${ }^{a}$ Volkmar Falk, MD, PhD, ${ }^{\mathrm{a}, \mathrm{b}}$ and Christoph Knosalla, MD, PhD ${ }^{\mathrm{a}, \mathrm{b}}$

\section{ABSTRACT}

Objectives: Tricuspid insufficiency $(\mathrm{TI})$ is the most common valvular complication following orthotopic heart transplantation ( $\mathrm{HTX}$ ) and in serious cases is associated with increased mortality. In this study, we analyze the possible variables influencing TI following HTx and aim to identify the most important risk factors and mechanisms responsible for functional TI development and progression.

Methods: We identified the incidence of TI within our institute in 857 of 1515 patients who underwent HTx using the biatrial anastomosis technique in the years between 1986 and 2010. The risk factors that could influence TI were retrospectively analyzed in detail in a representative group of 152 patients with identical TI distribution as found in the entire program. Patients of the group were subdivided into 2 groups according to the severity of $\mathrm{Tl}$ : patients with $\mathrm{TI}$ grade $\leq 2$ and those with $\mathrm{TI}$ grade $>2$. Impact on long-term survival (>15 years) was assessed.

Results: In univariable analysis, study variables such as age of recipient $(P=.027)$, donor to recipient right atrium anterior wall ratio $(P<.001)$, tricuspid annulus anterior to septal leaflet excursion ratio $(P=.001)$, dialysis $(P=.026)$, and total biopsy number $(P=.003)$ showed significant differences. The variables, height of recipient $(P=.080)$, body mass index donor to body mass index recipient ratio $(P=.080)$, and number of biopsies with more than moderate grade $(P=.067)$ showed a trend toward significance in the development of severe TI after HTx. In multivariable analysis, we found an independent significant association between TI after HTx and donor to recipient right atrium anterior wall ratio, number of biopsies, and dialysis.

Conclusions: Changes in tricuspid annulus geometry, number of biopsies, and dialysis are the most important risk factors for the development and progression of $\mathrm{TI}$ following cardiac transplantation. It could be prevented using modified operative techniques, noninvasive diagnostic modalities, and intensified ultrafiltration. In patients with biatrial anastomosis technique with generous atrial cuff, the presence of $\mathrm{TI}$ greater than grade 2 did not impact long-term survival. (JTCVS Open 2020;4:25-32)

Tricuspid insufficiency (TI) is a common valvular abnormality following cardiac transplantation. Both occurrence and severity of TI have been found to increase with time, and TI is associated with an increase in morbidity and mortality. ${ }^{1,2}$ Clinically significant TI results in symptoms such

From the a Department of Cardiothoracic and Vascular Surgery, Deutsches Herzzentrum Berlin, Berlin; ${ }^{\mathrm{b}}$ DZHK (German Centre for Cardiovascular Research), Partner Site Berlin, Berlin, Germany.

Received for publication July 25, 2020; revisions received July 25, 2020; accepted for publication July 28, 2020; available ahead of print Sept 10, 2020.

Address for reprints: Vüsal Hajiyev, MD, Sana-Herzzentrum Cottbus, Leipziger Straße 50, D-03048 Cottbus, Germany (E-mail: hvusal@hotmail.com).

2666-2736

Copyright (C) 2020 The Authors. Published by Elsevier Inc. on behalf of The American Association for Thoracic Surgery. This is an open access article under the CC BY-NCND license (http://creativecommons.org/licenses/by-nc-nd/4.0/).

https://doi.org/10.1016/j.xjon.2020.07.008

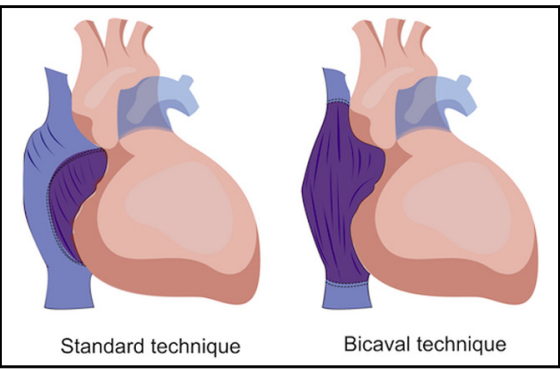

Tension on the anterior right atrial wall after HTX with standard and bicaval technique.

CENTRAL MESSAGE

To reduce incidence of $\mathrm{TI}$ after

$H T x$, right atrial anastomosis

should be done without tension, the number of biopsies have to be reduced and, if needed, dialysis must be done intensively.

\section{PERSPECTIVE}

Changes in tricuspid annulus geometry, number of biopsies, and dialysis are the most important risk factors for the development and progression of tricuspid insufficiency following cardiac transplantation.

See Commentaries on pages 33 and 35 . as edema, fatigue, and reduced tolerance of exertion. ${ }^{3}$ Diuretics are the common treatment method. In some instances, surgical tricuspid valve repair or replacement may be required. ${ }^{4}$

Based on mechanism of development, TI following heart transplantation (orthotopic) (HTx) can be divided into anatomic and functional. Functional TI is caused by geometric distortion or dilatation of the atrioventricular annular ring and valve leaflet malcoaptation. ${ }^{2,5,6}$ Anatomic TI is caused by torn leaflet, ruptured chordae, excessive leaflet motion, or degeneration of the valve apparatus. ${ }^{4}$

Many possible risk factors have been identified for the cause of TI after transplantation, but there is no consistency in the previous studies reporting risk factors. It has been reported that the existence of pulmonary hypertension and right ventricular injury during the operation can produce 


\section{Abbreviations and Acronyms \\ BMI = body mass index \\ $\mathrm{BSA}=$ body surface area \\ $\mathrm{EMB}=$ endomyocardial biopsy \\ HTx $=$ heart transplantation (orthotopic) \\ $\mathrm{TI}=$ tricuspid insufficiency}

right ventricular and tricuspid dilatation, which can lead to TI. Another risk factor that has been found to influence TI following HTx is high-grade allograft rejection. ${ }^{7}$ The surgical technique may also play a role. ${ }^{8} \mathrm{~A}$ mismatch in the heart size of the donor and the pericardial cavity of the recipient can be another risk factor for the development of tricuspid insufficiency by distortion of the geometry of tricuspid annulus. ${ }^{9}$ In some studies, it was found important to preserve the atrial geometry. ${ }^{2,5,6}$ Endomyocardial biopsy (EMB) was identified as a major risk factor of TI following HTx in the early 1990s. It was shown that injury of tricuspid valve apparatus at the time of EMB was a main cause of TI development. ${ }^{10}$ Several studies found a correlation between the number of biopsies and TI occurrence. ${ }^{11}$ A more recent study found associations between donor age and TI following HTx. ${ }^{12}$ In this study, we analyze the possible variables influencing TI following HTx and aim to identify the risk factors and mechanisms responsible for functional TI development and progression.

\section{METHODS}

In this retrospective, single-institution cohort study, we identified an institutional incidence of TI in 857 of 1515 patients who survived for at least 12 months, had available echocardiographic assessments, and had undergone HTx for the first time. We then performed an analysis of variables that potentially influence TI in a subgroup of patients, in which the detailed mechanisms of TI could be analyzed on echocardiography and allowed for long-term follow-up. This group was divided into 2 subgroups based on the severity of their postoperative TI: no TI to moderate (TI $\leq 2$ ) and severe (TI $>2$ ). These 2 groups were compared regarding underlying disease, sex, age, height, weight, body mass index (BMI), body surface area (BSA) of donor and recipients, organ ischemic time, preoperative pulmonary pressure, donor to recipient right atrium front wall ratio, tricuspid anterior to septal annulus systolic excursion ratio, ratio of thorax length to heart length on radiographs preoperatively, number of biopsies, the greatest rejection grade in biopsy, the number of biopsies with more than moderate reaction, and evidence of transplant microvasculopathy on biopsy or need for chronic dialysis.

Patients with structural TI (ie, torn or perforated leaflet and ruptured chordae as a complication of biopsy detected on echocardiogram) were excluded from this study. The chronic need for dialysis was also noted during the last 2 years of the study period. Orthotopic implantation of the donor heart was carried out using the Lower and Shumway technique as modified by Cooley and Barnard. ${ }^{13}$ To allow anastomosis without tension and preservation of the right atrial geometry, a generous right atrial cuff was used.

Quantification of TI was done by Doppler color flow imaging using the proximal convergence method, vena contracta imaging, and color jet mapping. Donor to recipient right atrium and anterior wall ratio was determined during transthoracic echocardiography in the modified apical 4-chamber view, where right atrium anterior wall can be viewed and lengths can be measured.

Tricuspid annulus anterior to septal systolic excursion ratio was calculated from data acquired in the 4-chamber view measuring the amount of longitudinal motion of the annulus in the anterior and septal part at peak systole. Preoperative thoracic and heart width ratio were determined on radiographs. Cardiac length was measured between the maximum transverse cardiac diameter and the maximal thoracic diameter as measured between the inner margins of the ribs.

Rejection monitoring was performed based on intramyocardial electrogram recordings and echocardiography. ${ }^{14}$ EMB was performed indicated by noninvasive tools. Biopsies were evaluated for rejection using the revised International Society for Heart and Lung Transplantation criteria. ${ }^{15}$ Evaluation of transplant vasculopathy was done by annual coronary arteriogram. Microvasculopathy was graded according to the classification we published previously. ${ }^{16}$

All procedures were carried out in accordance with the ethical standards of the Institutional Human Ethics Committee and with the Helsinki Declaration. This study was approved by our institutional review board, and the need for patient consent was waivered.

\section{Statistical Analysis}

The metric variables were represented as mean and median values, whereas the scattering measurements were expressed as standard deviations and quartiles. The scale variables were checked by the Kolmogorov-Smirnov test $(P \geq .05)$ in relation to their normal distribution. The $t$ test was used to compare 2 independent, normally distributed random samples. Previously, the Levene test was applied to verify the homogeneity of the variances. For non-normally distributed random samples, the MannWhitney $U$ test was used as a nonparametric method.

Categorical data were evaluated using the $\chi^{2}$ test or the Fisher exact test. In all the tests performed there was a 2 -sided significance testing, wherein a $P$ value $<.05$ was taken as statistically significant for all statistical tests. Survival curves were calculated by the Kaplan-Meier method and differences analyzed by the log-rank test. For multivariable analysis, binary logistic regression with Wald Statistics and inclusion-forward using the likelihood ratio criterion (including $P$ value $\leq .05 ; P$ value exclusion $>.1$ ) was performed. Data were analyzed using SPSS for Windows, version 22.0 (IBM Corp, Armonk, NY).

\section{RESULTS}

In the whole study group of 857 patients who were operated on between 1986 and 2010 and survived for at least 12 months, 38\% $(\mathrm{n}=327)$ had no TI, $43 \%(\mathrm{n}=369)$ TI I, $13 \% \mathrm{n}=(109)$ TI $2,5 \%(\mathrm{n}=42)$ TI 3 , and $1 \%$ $(\mathrm{n}=10)$ TI 4 (Figure 1). In the representative study group of 152 patients who came to annual control between 2000 and 2001, underwent HTx between 1986 and 2000, and survived for at least 12 months, the echocardiographic assessment showed $37 \%(\mathrm{n}=56)$ TI $0,43 \%(\mathrm{n}=65)$ TI I, $12 \%$ $(\mathrm{n}=19)$ TI $2,6 \%(\mathrm{n}=9)$ TI 3 , and $2 \%(\mathrm{n}=3)$ TI 4 . The distribution of TI in this group was very similar to that of the whole study group of 857 patients (Figure 1).

The subgroup was divided into 2 groups based on the severity of postoperative TI (TI $\leq 292.1 \% \mathrm{n}=140$ and TI $>27.9 \% \mathrm{n}=12$ ), and all variables were statistically compared in both groups. The majority of the recipients were male: $85.5 \%(\mathrm{n}=130)$ and $14.5 \%(\mathrm{n}=22)$ female. Most of the patients had dilative cardiomyopathy, $66.9 \%$ $(\mathrm{n}=101)$, and $27.2 \%(\mathrm{n}=41)$ had coronary artery disease. 

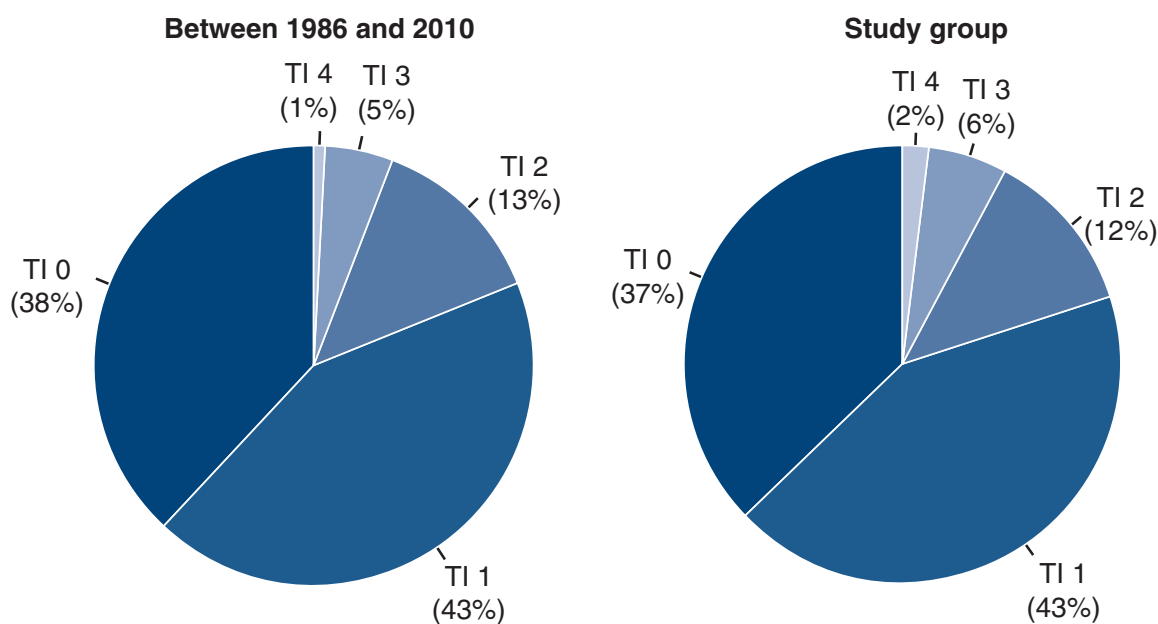

FIGURE 1. Left, Incidence of TI after HTx in Deutsches Herzzentrum Berlin between 1986 and 2010: TI $038 \%$ (n = 327), TI I 43\% (n= 369), TI 2 13\% $(\mathrm{n}=109)$, TI $35 \%(\mathrm{n}=42)$, TI 4 1\% $(\mathrm{n}=10)$ (TI Tricuspid insufficiency). Right, Incidence of TI after HTx in study group of 152 patients: TI $037 \%$ $(\mathrm{n}=56)$, TI I 43\% ( $\mathrm{n}=65)$, TI $212 \%(\mathrm{n}=19)$, TI $36 \%(\mathrm{n}=9)$, and TI $42 \%(\mathrm{n}=3)$. TI, Tricuspid insufficiency.

The median age for the group with $\mathrm{TI} \leq 2$ was 52.06 years. For the group with $\mathrm{TI}>2$, the median age was 43.05 years. Recipients who developed TI $>2$ were younger than those with $\mathrm{TI} \leq 2$, and the age of recipient showed significant relevance $(P=.027)$. There was no significance of height, weight, BMI, organ ischemia time, or BSA of recipient. Organic ischemic time also showed no significance.

The majority of donors were male, with $70.2 \%(\mathrm{n}=106)$ and $29.8 \%$ (45) were female. The median age of donors was 35 years. Height, weight, BMI, and BSA of donors showed no significance for developing severe TI following HTx.

Analysis of parameters that can cause functional TI showed the following results. Donor to recipient right atrial anterior wall ratio showed significance $(P<.05)$. Tricuspid annulus anterior to septal excursion ratio was also significant $(P<.05)$ for TI $>2$ following HTx. Dialysis is a pathologic factor that can play a role in atrial size enlargement. Even though only 10 patients of 152 required dialysis, in 7 $(5 \%)$ responders from the group with $\mathrm{TI} \leq 2$ and $3(27.3 \%)$ from TI $>2$, dialysis showed importance $(P=.026)$. BMI donors and BMI recipients showed a small trend for relevance. Thorax dimensions, heart on radiograph, and ratio was not significant, but the size of heart and chest were bigger in the TI $>2$ group (Table 1).

In our analysis of the variables concerning biopsy, the total number of biopsies was significant $(P=.003)$, whereas all other variables, such as greatest diagnosed grade of biopsy, number of biopsies with more than a moderate grade of rejection, and vascular reaction in biopsy, showed no significance (Table 2).

For multivariable analysis, binary logistic regression with Wald statistics and forward inclusion using the likelihood ratio criterion (including $P \leq .05 ; P$ value exclusion $>0.1$ ) was performed. Parameters included for multivariable analysis are as follows: age of recipient, donor/recipient anterior wall ratio basic disease, height of recipient, total biopsy number, degree of allograft microvasculopathy, and dialysis and BMI donor/BMI recipient. Because of the valid number of only 98 , anterior or septal leaflet excursion ratio were not taken in regression. With the $P<.05$ in binary logistic regression, it is evident that the donor/recipient anterior wall ratio, biopsy number, and dialysis have

TABLE 1. Parameters that can cause functional TI after cardiac transplantation

\begin{tabular}{lccc}
\hline & TI $\leq \mathbf{2}$ & TI $>\mathbf{2}$ & $\boldsymbol{P}$ value \\
\hline Donor recipient anterior wall ratio & $0.85 \pm 0.14, \mathrm{n}=140$ & $1.17 \pm 0.19, \mathrm{n}=12$ & $<.001$ \\
Anterior septal leaflet excursion ratio & $1.37 \pm 0.48, \mathrm{n}=89$ & $0.84 \pm 0.38, \mathrm{n}=9$ & .001 \\
Chest radiograph width thorax recipient, $\mathrm{cm}$ & $28.09 \pm 3.58, \mathrm{n}=122$ & $30 \pm 3.85, \mathrm{n}=8$ & .217 \\
Chest radiograph width heart recipient, cm & $16.43 \pm 2.72, \mathrm{n}=122$ & $17.88 \pm 2.75, \mathrm{n}=8$ & .131 \\
Radiograph thorax heart ratio recipient & $1.73 \pm 0.23, \mathrm{n}=122$ & $1.69 \pm 0.16, \mathrm{n}=8 \quad .12 \pm 0.16, \mathrm{n}=10$ & .724 \\
BMI donor to BMI recipient ratio & $1.02 \pm 0.20, \mathrm{n}=133$ & .080 \\
Dialysis, yes $(\mathrm{n}) / \mathrm{no}(\mathrm{n})$ & $7 / 133$ & .026 \\
\hline
\end{tabular}

Values are mean \pm standard deviation. $T I$, Tricuspid insufficiency; $B M I$, body mass index. 
TABLE 2. Parameters that can cause anatomic TI after HTx

\begin{tabular}{lccc}
\hline & TI $\leq \mathbf{2}$ & TI $>\mathbf{2}$ & $\boldsymbol{P}$ value \\
\hline Total biopsy number & $9.11 \pm 10.86, \mathrm{n}=140$ & $26.92 \pm 22.94, \mathrm{n}=12$ & .003 \\
Highest biopsy grade & $1.36 \pm 1.19, \mathrm{n}=140$ & $1.92 \pm 1.16, \mathrm{n}=12$ & .123 \\
$\begin{array}{l}\text { Number of biopsies with more } \\
\text { than moderate grade }\end{array}$ & $0.56 \pm 1.14, \mathrm{n}=140$ & $2.08 \pm 3.23, \mathrm{n}=12$ & .067 \\
$\begin{array}{l}\text { Transplant } \\
\quad \text { microvasculopathy }\end{array}$ & $5.66 \pm 2.72, \mathrm{n}=137$ & $6.58 \pm 2.35, \mathrm{n}=12$ & .144 \\
\hline Values are mean \pm sandard deviation TI, Tricuspid insufficiency. & & \\
\end{tabular}

Values are mean \pm standard deviation. TI, Tricuspid insufficiency.

independent associations to TI (Table 3). The KaplanMeier analysis with log rank test value $<0.05$ showed no significant difference in long-term mortality of patients with $\mathrm{TI} \leq 2$ and $\mathrm{TI}>2$ (Figure 2).

\section{DISCUSSION}

TI is a frequent complication following cardiac transplantation. It develops with time, has clinical significance, and can lead to decreased quality of life and mortality. ${ }^{3,17}$ The factors responsible for the development of TI following HTx widely reported in the literature are age, ischemic time, time after operation, steroid use, number of rejections, pulmonary hypertension, operative technique, donor/recipient size miss match, coronary artery vasculopathy, and the use of dialysis. ${ }^{7,12,18-23}$

Incidence of TI was retrospectively examined in 857 of 1515 patients. Thirty-eight percent, or $\mathrm{n}=327$, of patients had no TI, $43 \%(\mathrm{n}=369)$ TI I, $13 \%(\mathrm{n}=109)$ TI $2,5 \%$ $(\mathrm{n}=42)$ TI 3 , and $1 \%(\mathrm{n}=10)$ TI 4 . Earlier study reports show that up to $98 \%$ of patients are affected by TI of any grade. It is complicated to compare the prevalence of TI following HTx between various studies due to differences in follow-up periods, definitions of significant TI, and procedures used to identify TI. ${ }^{23,24}$ Significant cases of TI following HTx are defined as TI greater than moderate (greater than grade 2). The average follow-up time for our study was 9 years.

In our study, the majority of patients who underwent heart transplantation were male $(\mathrm{n}=130,85.5 \%)$, although results indicate that there is no association between TI and sex $(P=.686)$. This finding is in line with the results of retrospective case-control studies by Najib and colleagues. ${ }^{25}$

TABLE 3. Variables with independent association to TI after HTx in logistic regression

\begin{tabular}{lcc}
\hline & Wald & $\boldsymbol{P}$ value \\
\hline $\begin{array}{l}\text { Donor/recipient anterior } \\
\text { wall ratio }\end{array}$ & 12.081 & .001 \\
Total biopsy number & 6.263 & .012 \\
Dialysis & 7.391 & .007 \\
\hline
\end{tabular}

Number included $\mathrm{N}=140$, missing $\mathrm{N}=12$.
In our study, univariable analysis revealed that there was a significant difference in TI between different recipient age groups $(P=.027)$. Patients with $\mathrm{TI}>2($ mean $=42.40)$ were younger than those with TI $\leq 2$ (mean $=49.55)$. This contradicts the results of Lewen and colleagues. ${ }^{26}$ Sun and colleagues ${ }^{27}$ found that the age of the recipient is a significant predictor of acute cardiac allograft rejection. It can indirectly affect TI by the necessity of EMB, the number of which is another significant variable. In contrast, younger age as a risk factor can be explained by the progressive character of TI following HTx with time. The study shows no significance of donor age group. The mean age of donors was 35.28 (standard deviation \pm 13.78 ) years and the maximum age was 65 years.

Tricuspid annulus geometry after cardiac transplantation is an important factor in developing TI after heart transplantation. ${ }^{6}$ De Simone and colleagues ${ }^{5}$ found an importance of $\mathrm{TI}$ and the recipient atrial dimensions and recipient to donor right atrium ratio. Our echocardiographic assessments showed that donor to recipient anterior wall ratio $>1$ correlates with the position of the tricuspid leaflets, which causes TI with an eccentric jet. This is atypical for annular dilatation, which is the main finding in patients with TI who did not undergo cardiac transplantation. We found that preservation of the long recipient right atrial anterior wall segments (donor/recipient $<1$ ) and abundant lateral donor atrial length in comparison to the septal length is of paramount importance (Figure 3).

Haverich and colleagues ${ }^{9}$ demonstrate that TI following HTx can occur because of a mismatch between the donor heart and recipient pericardial cavity. Hausen and colleagues ${ }^{28}$ show that the weight of the donor heart can play an important role in the incidence of TI following HTx. We measured the width of the heart and the chest on preoperative radiographs and calculated their ratios. It showed no significance, but the width of the chest and heart was bigger in patients with TI $>2$ (mean $30 \pm 3.85,17.88 \pm 2.75$, respectively) than those with $\mathrm{TI} \leq 2$ (mean $28.9 \pm 3.58$, $16.43 \pm 2.72$ respectively). The other parameters (weight, BMI, and BSA of donors and recipients) showed no significance. Trend to significance was shown by the donor-torecipient BMI ratio $(P=.080)$ and height of recipient $(P=.073)$ patients. 


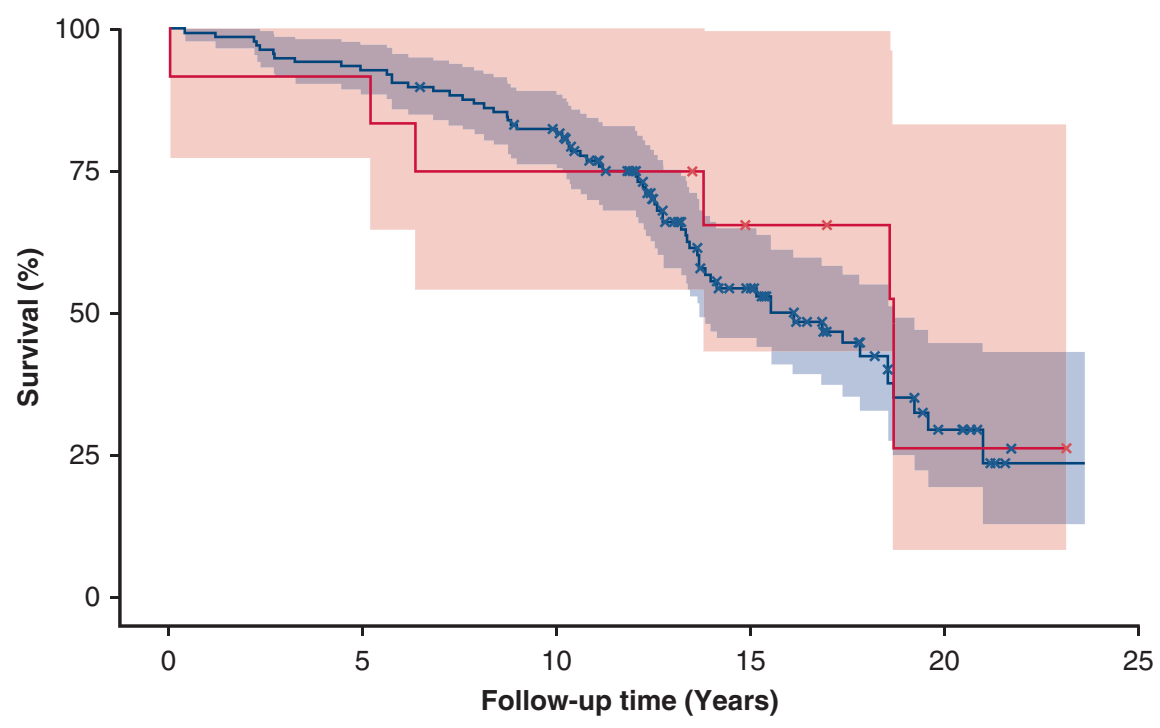

Numbers at risk

\begin{tabular}{c|cccccc}
$\leq 2$ & 137 & 127 & 109 & 40 & 9 & 0 \\
$>2$ & 12 & 11 & 9 & 6 & 2 & 0
\end{tabular}

FIGURE 2. Kaplan-Meier survival of patients with $\mathrm{TI} \leq 2$ or $\mathrm{TI}>2$ conditional on surviving to at least 1 year after HTx.
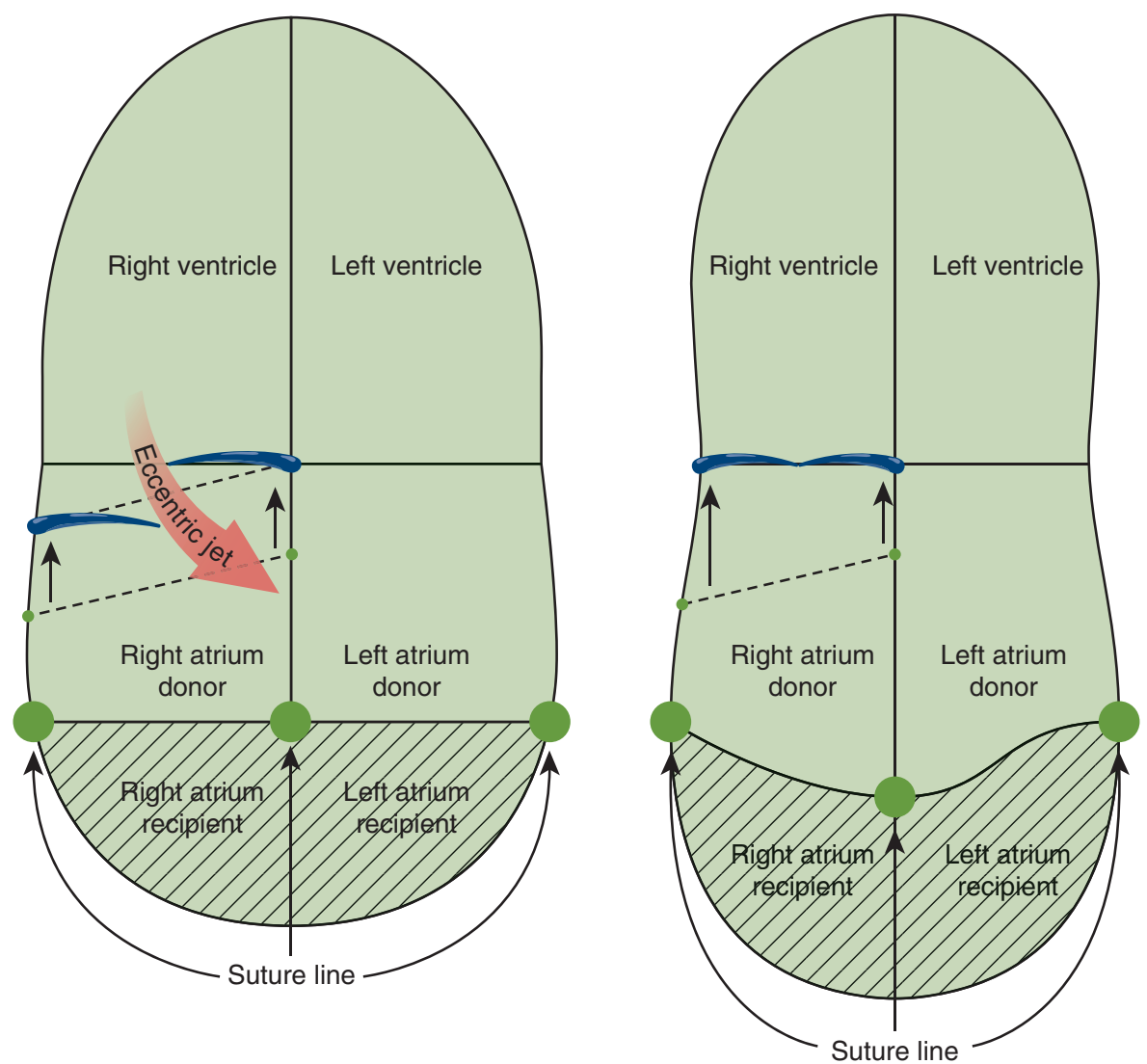

FIGURE 3. Schematic mechanism of tricuspid valve insufficiency in a heart transplant recipient as seen in echocardiography four chamber view. Left, Transplanted heart with donor/recipient anterior atrial wall length ratio $>1$ with typical eccentric jet, malposition and malcoaptation of valve leaflets due to traction in the right atrium. Right, transplanted heart with right donor/recipient anterior atrial wall length ratio $<1$ where no traction present. 
Many studies reveal a correlation between TI and pulmonary pressure, ${ }^{7,23,26,28}$ but others indicate that there is no association between preoperative pulmonary artery pressure and postoperative TI. In line with the latter studies, our study shows no significance between preoperative pulmonary pressure and the development of TI during long-term follow-up. ${ }^{7,24,28}$

Dialysis is another pathologic factor shown as a risk factor for developing TI following HTx in 2 studies. ${ }^{9,26}$ Kim and colleagues ${ }^{29}$ report a case of spontaneous chordae rupture and shortened papillary muscle of the tricuspid valve of a patient on dialysis. Even though only small number $(\mathrm{n}=10)$ of patients were dialyzed, it showed significance $(P=.026)$. The effect of dialysis on TI can be explained by changes in tricuspid valve anatomy and volume overload.

Many studies compare operative techniques and their effect on TI after cardiac transplantation. Even though the bicaval technique seems superior to the standard technique, TI remains significant regardless of what technique is used. ${ }^{8}$ Different modification advice is given to reduce TI following HTx for the standard and bicaval techniques. All modifications concentrate on leaving enough material in the right atrium to reduce tension and preserve the geometry of the tricuspid annulus in order to reduce TI. ${ }^{24,30}$ In our institution, a modified standard technique with a generous atrial cuff where the cut line of the recipient's atrium starts posterior to the vena cava inferior with a curved incision to the right atrial appendage (Figure 4) was used. This may explain the relatively low incidence of TI following HTx compared to that in other centers.

The importance of EMB on the development of TI has been emphasized in many studies. ${ }^{24,28,31}$ Our study found no correlation between greatest biopsy grade, number of biopsies with more than moderate grade, cardiac allograft microvasculopathy, and occurrence of TI. But the number of biopsies $(P=.003)$ in univariable analysis was significant. This result is consistent with that identified by Hausen colleagues, ${ }^{28}$ Nguyen and colleagues, ${ }^{11}$ and Lo and colleagues. ${ }^{32}$ Fiorelli and colleagues ${ }^{33}$ found tricuspid valve tissue in 12 of 417 patients after an EMB and TI was increased in 2 of these cases afterward (2/12;16.7\%). The mechanism of developing TI following HTx due to the number of biopsies can be explained by microscopic damage and changes in the structure of the valve apparatus which are not detectable at the time of echocardiographic evaluation and have a cumulative character. The small changes on tricuspid valve apparatus of transplanted hearts after EMB should be further investigated. The multivariable analysis shows that donor to recipient anterior wall ratio, number of biopsies, and dialysis have independent significance for TI following HTx.

There was no significance in survival between the 2 groups. It is possible that even patients with TI $>2$ benefit

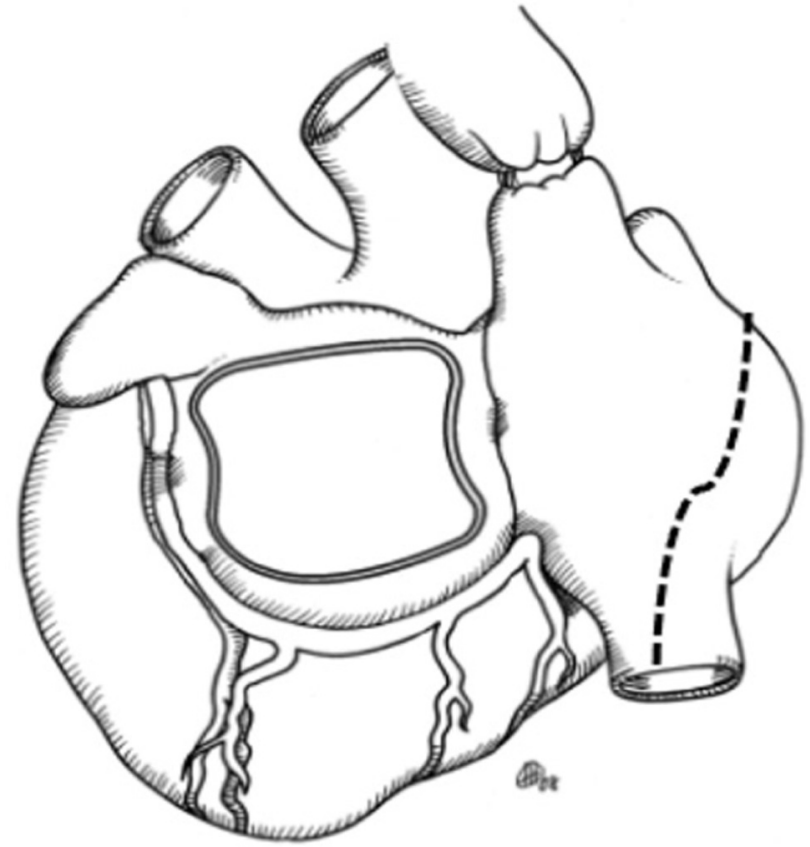

FIGURE 4. The cut line of the recipient's atrium, which starts posterior to the vena cava inferior with a curved incision to the right atrial appendage to leave generous atrial cuff.

from an implantation technique using a large atrial cuff, as it may serve as a compliance chamber.

It is to be acknowledged that the current study has certain limitations. By its nature, it is subject to the restrictions of a retrospective study. Due to the long period over which the study patients were treated, the population is certainly heterogeneous. The severity of TI was graded by measuring the regurgitant jet area size on color Doppler. The major limitation of this grading is that it does not yield quantitative data.

\section{CONCLUSIONS}

Our study shows no significance concerning recipient sex, basic disease, recipient weight, recipient BMI, recipient BSA, preoperative pulmonary arterial pressure, donor organ ischemia time, donor sex, donor age, donor height, donor weight, donor BMI, donor BSA, chest radiograph thorax width, chest radiograph heart width, chest radiograph thorax/heart ratio, highest rejection grade on biopsy, or vascular reaction.

The significance of parameters that impact functional TI, such as right atrium to front wall ratio and dialysis in multivariable analysis, significance of tricuspid annulus anterior to septal leaflet excursion in univariable analysis, and trend to significance of factors such as BMI donor to recipient ratio, gives us reason to conclude that the tricuspid annulus geometry is an important risk factor for developing TI following HTx. It could be preserved using operative techniques that do not create tension on the atrial wall, for 
example, by using modified inferior vena cava anastomosis with the bicaval technique or a generous atrial cuff with the standard biatrial technique. ${ }^{24,30}$

Patients with functional TI and end-stage renal disease requiring dialysis could be treated using intensified ultrafiltration. Cirit and colleagues ${ }^{34}$ showed disappearance or reduction of TI in patients with end-stage renal disease using intensified, aggressive ultrafiltration and discontinuing antihypertensive drugs.

The number of biopsies is also a significant risk factor for TI. It is advisable to use noninvasive diagnostic modalities for detection of rejection, such as echocardiography, intramyocardial electromyography, and gene expression profiling to reduce the number of EMB cases and to prevent TI following HTx..$^{20,27,35,36}$

\section{Conflict of Interest Statement}

V. Falk discloses financial relationships with the following entities: Medtronic GmbH, Biotronik SE \& Co, Abbott GmbH \& Co KG, Boston Scientific, Edwards Lifesciences, Berlin Heart, Novartis Pharma GmbH, JOTEC GmbH, and Zurich Heart. All other authors reported no conflicts of interest.

The Journal policy requires editors and reviewers to disclose conflicts of interest and to decline handling or reviewing manuscripts for which they may have a conflict of interest. The editors and reviewers of this article have no conflicts of interest.

Vüsal Hajiyev owes the deepest gratitude to the staff of Deutsches Herzentrum, Berlin, especially to the surgeons who performed transplantations there.

\section{References}

1. Knosalla C, Schmitt-Knosalla I, Yeter R, Hetzer R. Impact of surgical techniques on long-term results after heart transplantation. Thorac Cardiovasc Surg. 2009; 57:159-61.

2. Urbanowicz T, Michalak M, Kociemba A, Straburzynska-Migaj E, Katarzynski S, Grajek S, et al. Predictors of tricuspid valve anulus dilation in a heart recipient population. Transplant Proc. 2016;48:1742-5.

3. Aziz TM, Saad RA, Burgess MI, Campbell CS, Yonan NA. Clinical significance of tricuspid valve dysfunction after orthotopic heart transplantation. J Heart Lung Transplant. 2002;21:1101-8.

4. Wong RC-C, Abrahams Z, Hanna M, Pangrace J, Gonzalez-Stawinski G, Starling R, et al. Tricuspid regurgitation after cardiac transplantation: an old problem revisited. J Heart Lung Transplant. 2008;27:247-52.

5. Simone R, Lange R, Sack RU, Mehmanesh H, Hagl S. De Atrioventricular valve insufficiency and atrial geometry after orthotopic heart transplantation. Ann Thorac Surg. 1995;60:1686-93.

6. Dandel M, Hummel M, Loebe M. Right atrial geometry and tricuspid regurgitation after orthotopic heart transplantation: benefits of a modified biatrial surgical technique. J Heart Lung Transplant. 2001;20:246-7.

7. Aziz TM, Burgess MI, Rahman AN, Campbell CS, Deiraniya AK, Yonan NA. Risk factors for tricuspid valve regurgitation after orthotopic heart transplantation. Ann Thorac Surg. 1999;68:1247-51.

8. Schnoor M, Schäfer T, Luhmann D, Sievers HH. Bicaval versus standard technique in orthotopic heart transplantation: a systematic review and meta-analysis. J Thorac Cardiovasc Surg. 2007;134:1322-31.
9. Haverich A, Albes JM, Fahrenkamp G, Wahlers T, Heublein B, Schäfers HJ, et al. Intraoperative echocardiography to detect and prevent tricuspid valve regurgitation after heart transplantation. Eur J Cardiothorac Surg. 1991;5:41-5.

10. Braverman AC, Coplen SE, Mudge GH, Lee RT. Ruptured chordae tendineae of the tricuspid valve as a complication of endomyocardial biopsy in heart transplant patients. Am J Cardiol. 1990;66:111-3.

11. Nguyen V, Cantarovich M, Cecere R, Giannetti N. Tricuspid regurgitation after cardiac transplantation: how many biopsies are too many? J Heart Lung Trans plant. 2005;24(7 suppl):S227-31.

12. Kim GS, Kim JJ, Kim JB, Kim DH, Song JM, Yun TJ, et al. Fate of atrioventricular valve function of the transplanted heart. Circ J. 2014;78:1654-60.

13. Cooley DA, Messmer BJ, Hallman GL, Leachman RD, Rochelle DG. Technique and results of human heart transplantation. Langenbecks Arch Chir. 1969;326: 5-24.

14. Park JW, Warnecke H, Deng M, Schuler S, Heinrich KW, Hetzer R. Early diastolic left ventricular function as a marker of acute cardiac rejection: a prospective serial echocardiographic study. Int J Cardiol. 1992;37:351-9.

15. Stewart S, Winters GL, Fishbein MC, Tazelaar HD, Kobashigawa J, Abrams J, et al. Revision of the 1990 working formulation for the standardization of nomenclature in the diagnosis of heart rejection. J Heart Lung Transplant. 2005;24: 1710-20.

16. Hiemann NE, Wellnhofer E, Knosalla C, Lehmkuhl HB, Stein J, Hetzer R, et al. Prognostic impact of microvasculopathy on survival after heart transplantation: evidence from 9713 endomyocardial biopsies. Circulation. 2007;116:1274-82.

17. Marelli D, Esmailian F, Wong SY, Kobashigawa JA, Kwon MH, et al. Tricuspic valve regurgitation after heart transplantation. Cardiovasc Surg. 2009;6:557-9.

18. Akasaka T, Lythall DA, Kushwaha SS, Yoshida K, Yoshikawa J, Yacoub MH, et al. Valvular regurgitation in heart-lung transplant recipients: a Doppler color flow study. J Am Coll Cardiol. 1990;15:576-81.

19. Kalra N, Copeland JG, Sorrell VL. Tricuspid regurgitation after orthotopic heart transplantation. Echocardiography. 2010;27:1-4.

20. Sade LE, Sezgin A, Uluçam M, Taymaz S, Simşek V, Tayfun E, et al. Evaluation of the potential role of echocardiography in the detection of allograft rejection in heart transplant recipients. Transplant Proc. 2006;38:636-8.

21. Sun JP, Niu J, Banbury MK. Influence of different implantation techniques on long-term survival after orthotopic heart transplantation: an echo cardio graphic study. Lung Transpl. 2005;26:1243-8.

22. Park KY, Park CH, Chun YB, Shin MS, Lee KC. Bicaval anastomosis reduces tricuspid regurgitation after heart transplantation. Asian Cardiovasc Thorac Ann. 2005;13:251-4.

23. Berger Y, Har Zahav Y, Kassif Y, Kogan A, Kuperstein R, Freimark D, et al Tricuspid valve regurgitation after orthotopic heart transplantation: prevalence and etiology. J Transplant. 2012;2012:120702.

24. Yankah AC, Musci M, Weng Y, Loebe M, Zurbruegg HR, Siniawski H, et al Tricuspid valve dysfunction and surgery after orthotopic cardiac transplantation. Eur J Cardiothorac Surg. 2000;17:343-8.

25. Najib MQ, Vittala SS, Challa S, Raizada A, Tondato FJ, Lee HR, et al. Predictors of severe tricuspid regurgitation in patients with permanent pacemaker or automatic implantable cardioverter-defibrillator leads. Tex Heart Inst J. 2013;40: 529-33.

26. Lewen MK, Bryg RJ, Miller LW, Williams GA, Labovitz AJ. Tricuspid regurgitation by Doppler echocardiography after orthotopic cardiac transplantation. Am J Cardiol. 1987:59:1371-4.

27. Sun JP, Abdalla IA, Asher CR, Greenberg NL, Popović ZB, Taylor DO, et al. Noninvasive evaluation of orthotopic heart transplant rejection by echocardiography. J Heart Lung Transplant. 2005;24:160-5.

28. Hausen B, Albes JM, Rohde R, Demertzis S, Mugge A, Schafers HJ. Tricuspid valve regurgitation attributable to endomyocardial biopsies and rejection in heart transplantation. Ann Thorac Surg. 1995;59:1134-40.

29. Kim H, Cho YK, Nam CW, Han SW, Hur SH, Kim YN, et al. Spontaneous chordae rupture of tricuspid valve in patient with chronic renal failure. Eur J Echocardiogr. 2008;9:58-9.

30. Marelli D, Silvestry SC, Zwas D, Mather P, Rubin S, Dempsey AF, et al. Modified inferior vena caval anastomosis to reduce tricuspid valve regurgitation after heart transplantation. Heart Inst J. 2007;34:30-5.

31. Williams MJ, Lee MY, DiSalvo TG. Biopsy-induced flail tricuspid leaflet and tricuspid regurgitation following orthotopic cardiac transplantation. Am J Cardiol. 1996;77:1339-44. 
32. Lo C-Y, Chang H-H, Hsu C-P, Lai S-T, Shih C-C. Endomyocardial biopsy-related tricuspid regurgitation after orthotopic heart transplantation: single-center experience. J Chin Med Assoc. 2007;70:185-92.

33. Fiorelli AI, Coelho GHB, Oliveira JL, Aiello VD, Benvenuti LA, Santos A, et al. Endomyocardial biopsy as risk factor in the development of tricuspid insufficiency after heart transplantation. Transplant Proc. 2009;41:935-7.

34. Cirit M, Ozkahya M, Cinar CS, Ok E, Aydin S, Akcicek F, et al. Disappearance of mitral and tricuspid regurgitation in haemodialysis patients after ultrafiltration. Nephrol Dial Transplant. 1998;13:389-92.

35. Knosalla C, Grauhan O, Muller J, Pfitzmann R, Fietze E, Cohnert T, et al. Intramyocardial electrogram recordings (IMEG) for diagnosis of cellular and humoral mediated cardiac allograft rejection. Ann Thorac Cardiovasc Surg 2000;6:89-94.

36. Starling RC, Pham M, Valantine H, Miller L, Eisen H, Rodriguez ER, et al. Molecular testing in the management of cardiac transplant recipients: initial clinical experience. J Heart Lung Transplant. 2006;25: 1389-95.

Key Words: cardiac transplantation, tricuspid valve insufficiency, myokardial biopsy, operative technique of cardiac transplantation, right atrial geometry 